\title{
Clarice Lispector e a literatura brasileira no mapa literário europeu
}

\author{
Lucilene MACHADO GARCIA ARF \\ Universidade Estadual Paulista "Julio de Mesquita Filho" \\ lucilenemachado@terra.com.br
}

\begin{abstract}
RESUMO
Esse pequeno inventário da produção literária brasileira na Espanha, impulsionada pela forte presença de Clarice Lispector, demonstra que a literatura anteriormente conhecida como muito próxima à oralidade e vinculada a uma realidade sociológica, passa a se destacar por suas características estéticas. Longe do folclore e da oralidade, a obra clariciana é edificada na linguagem e nas relações humanas, mais especificamente na alma feminina, o que permite inverter os processos de apropriação literária feita pelo Brasil enquanto ex-colônia. A produção clariciana penetrará uma elite européia, que inclui a espanhola, que passará a discutir e analisar as formas de recepção relacionadas às instâncias de produção, circulação e apropriação literárias.
\end{abstract}

Palavras chave: Clarice Lispector, literatura brasileira

[Recibido, septiembre 2010; aprobado, diciembre 2010]

\section{Clarice Lispector and the Brazilian literature in the European literary context}

\begin{abstract}
This small inventary of the Brazilian literary production in Europe, propelled by the string presence of Clarice Lispector, shows how Brazilian literature, formerly known as being close to orality and linked to a sociological reality, is now appreciated thanks to its aesthetic features. Lispector's work is built on human language and relationships, as well as the feminine soul; her work will penetrate the European elite -including the Spanish one.
\end{abstract}

Keywords: Clarice Lispector, Brazilian literature, European cultural elite

Já há algum tempo o Brasil se colocou no mercado espanhol como um agente de bens simbólicos e culturais, exportando músicas, danças, telenovelas, cinema e também as chamadas "artes impuras" que circulam nos circuitos minoritários a que foram destinadas, como é o caso de vídeos, revistas que exploram o carnaval e a sensualidade da mulher brasileira.

A literatura, apesar de oferecer uma variedade de gênero, não deixou raízes profundas na Espanha e, quiçá, na Europa. Isso se deve a diversos fatores, que merecem uma discussão aprofundada, mas os principais deles estão ligados à 
língua. A socióloga francesa Pascale Casanova, em seu livro La Republique mondiale des Lettres (1999), defende a idéia de que a literatura pode ser pensada em termos de mapas mundiais, distribuídos conforme a área lingüística de cada produção. Nessa república de letras, a literatura brasileira pertence à área do português e, portanto, situa-se na periferia, ou conforme ela mesma sustenta, é uma literatura excêntrica. Isso explica o fato de a literatura sul-americana, nossa vizinha geograficamente, tornar-se comercialmente tão interessante na Europa, o mapa lingüístico é o espanhol que está em uma posição muito superior a do nosso idioma, além de poder entrar na Espanha sem a necessidade de tradução.

Os estudos mais recentes da recepção têm demonstrado que a literatura hispano- americana tem obtido grandes projeções na Espanha desde o ano de 1967 quando o guatemalteco Miguel Ángel Asturias ganhou o prêmio Nobel de literatura. No mesmo ano surgiu Cem anos de solidão de Gabriel Garcia Marques, que em pouco tempo se converteu em um best-seller. Nos anos seguintes vieram as publicações de Isabel Allende, Octavio Paz e Mario Vargas Llosa. Não há dúvidas de que a literatura hispano-americana gozou de muita popularidade nesses anos, alavancando a literatura sul-americana de língua espanhola.

O Brasil não se beneficiou do famoso boom latino americano que atribuiu fama a García Marques, Vargas Llosa ou Borges. Lawrence Venuti em sua obra Escândalos da tradução, assegura que:

O boom foi em grande parte um aumento nas traduções das literaturas hispânicas que negligenciou as evoluções brasileiras contemporâneas: entre 1960 e 1979, as editoras britânicas e americanas publicaram 330 traduções do espanhol, mas somente 64 traduções do português brasileiro. (2002:318).

Venuti reitera que o boom envolveu certa predileção pela literatura produzida por homens. O que talvez corresponda a um conceito machista de autoria na cultura americana, considerando que a escritora Silvina Ocampo, esposa de Adolfo Bioy Casares, que produziu uma literatura tão implacavelmente inovadora quanto a de seus colegas, só foi traduzida para o inglês em 1980. "Foi durante o mesmo período que o trabalho muito aclamado da brasileira Clarice Lispector começou a aparecer em inglês" (Venuti, 2002: 319). Segundo a professora Gilda Oswaldo Cruz:

O Brasil não teve a vantagem de contar, como seus vizinhos de continente, com a vigorosa caixa de ressonância que a renascida Espanha dos finais da década de sessenta significou para os países do sul. O empobrecido Portugal imerso, até 1975, na letargia salazarista, não pôde funcionar como porta literária para sua ex-colônia. (2001: 14)

O português apesar de ter evoluído do galego, idioma falado na Galícia- ES, é ainda visto, por parte dos espanhóis, como uma língua "rara", uma insularidade geográfica e cultural diante das Américas hispânicas. Em geral, as publicações 
brasileiras foram bastante fragmentadas, poucos títulos por autor e por diferentes editoras, o que não permitiu ao público espanhol a oportunidade de constituir uma opinião mais precisa sobre a narrativa brasileira, dificultando o trabalho dos críticos em relacionar as novas traduções com as publicações anteriores; tínhamos então, apenas uma porção de nomes soltos. Sem contar que as publicações brasileiras, publicadas antes de Clarice, compunham-se, em sua maioria de uma literatura romântica e realista/naturalista que se afinam com os relatos de viagem, populações coloniais, sejam elas índios, escravos ou negros, ou aspectos relacionados com a vegetação, ecossistema, como é o caso de Jorge Amado e Raquel de Queirós, cuja literatura está voltada para temática do nordeste e romance social.

Antonio Maura, em artigo publicado na Revista de Cultura Brasileña, $\mathrm{n}^{\circ} 5$ (2007), adverte que na década de sessenta a literatura brasileira era praticamente desconhecida na Espanha. Nem mesmo os autores do regionalismo haviam sido traduzidos para a Península espanhola, com exceção de Lins do Rêgo com a obra Cangaceiros, editada em 1957 com tradução de A. Fernandes pela editora Caralt de Barcelona. Entretanto em 1963, um artigo publicado na antiga Revista de Cultura Brasileña, fazia referência ao escritor Guimarães Rosa. Ángel Crespo, que traduziria Grandes sertões veredas três anos depois, falava de um autor que descrevia o sertão brasileiro e seus habitantes de um ponto de vista tão pessoal que superava de uma só vez a tradição brasileira do romance regionalista. No mesmo artigo, Crespo acrescenta que a particularíssima linguagem de Rosa era praticamente intraduzível, algo que o próprio crítico faria posteriormente para oferecer aos espanhóis a única tradução de uma das mais importantes obras brasileiras.

La originalidad de Guimarães Rosa consiste en no plantear ni andar buscando problemas que puedan parecer originales sino, antes bien, en proponer las eternas preguntas del hombre, pero en el sertón. Así ocurre que Riobaldo, el protagonista y narrador de esta novela, vive obsesionado por los problemas del bien y del mal, de Dios y del diablo, del uranismo y el amor a derechas, de la afirmación de la propia personalidad. Nacida de su mismo espíritu, estas inquietudes no le han sido propuestas por el bosque pero, naturalmente, la circunstancia - por ejemplo, la de convertirse en jagunço (yagunzo) o bandolero - sí que le es proporcionada por el sertón en el que vive. João Guimarães Rosa no ha olvidado, como es el caso de bastantes regionalistas, que lo principal al hablar del hombre son sus eternos y casi invariables problemas. (Crespo, apud Maura, 2007)

Em junho de 1967, a Revista de Cultura Brasileña no 27 é dedicada a Guimarães Rosa, Ángel Crespo então diretor da publicação, relata sua viagem ao interior de Minas Gerais, passando pelos lugares mencionados nos textos de Rosa, bem como 
a difícil tarefa de traduzi-lo. Também fazem parte da encadernação outros autores como Renard Pérez e Julio E. Miranda. ${ }^{1}$ Em 1969, é publicado Primeras historias também pelo selo da Seix Barral de Barcelona e depois ficará por muitos anos praticamente esquecido.

Nos anos setenta, o autor brasileiro mais popular na Espanha era Jorge Amado, com sua obra, Los viejos marineros, editada em 1971 com tradução de Basílio Losada. Recordemos também que em 1974, outro grande nome do regionalismo, Graciliano Ramos teve o seu Vidas secas traduzido por José Luis Días de Liaño para a Colección Austral de Espasa Calpe.

O fato de não haver, até então, a difusão de um número relativo de obras literárias, acarretou em dificuldades para se avaliar a recepção da literatura brasileira enquanto fenômeno coletivo. O máximo que se fez foi uma análise restrita dessa literatura enquanto reação individual. Outro fator relevante foi que, a partir de 1964, instalou-se no Brasil um regime ditador militar que durante vinte e um anos dificultou o envio da boa literatura produzida continuamente no Brasil, para o exterior.

Embora alguns aficionados pela literatura brasileira, na Espanha, tenham se desdobrado para o reconhecimento da mesma durante os anos setenta, apenas nos finais dos anos 80 a produção brasileira começa a ganhar projeção. Coincidentemente é também nessa época o inicio da fase mais internacionalista na história das artes brasileiras. Um contexto de mudanças que recoloca nossa condição humana de forma diferente, já que não apenas o Brasil, mas todo o nosso entorno geográfico passa por transformações. Os conceitos de espaço e tempo vão se modificando substancialmente por conta do desenvolvimento dos meios tecnológicos, informativos e pela própria comunicação. São circunstâncias históricas que afetam a estética, sintomaticamente, com o fim dos anos 80 e a configuração de um novo modelo histórico com características diferenciadas não apenas no Brasil, pois a adaptação à globalização passa a ser prioridade mundial. As transformações socioeconômicas, a internacionalização da economia, o ajuste neoliberal (depois da queda do muro de Berlim) chegam também ao Brasil, inclusive com o escandaloso governo de Fernando Collor e, em seguida, as

${ }^{1}$ O número agrega os seguintes estudos: "Guimarães Rosa”, de Renard Pérez, "Modos, lenguaje y sentido em Gran sertón: veredas, de João Guimarães Rosa" de Julio E. Miranda, "Elementos geográficos en Gran sertón: veredas. Algunos aspectos" de Silvia Moodie, "El quehacer poético de Guimarães Rosa" de Sandra Márcia Haute y "Notas sobre las versiones y traducciones de Gran sertón:veredas", de Pilar Gomes Bedate. A revista se completa com uma carta do próprio Guimarães Rosa ao então embaixador do Brasil na Espanha, Antônio C. Cámara Canto, e o texto "Poshomenaje introductorio", de Ángel Crespo e sua tradução de cinco textos do autor mineiro: "La ceguera", de Sagarana; "Cara de bronce", de Corpo de baile; El juicio de Zé Bebelo", de Grandes sertões: veredas; "Los hermanos Dagobé" e "Ninguno, ninguna" de Primeiras estórias. 
mudanças de rumos tecnocráticos com o governo de Fernando Henrique Cardoso e a definitiva vitória sobre a inflação.

Diante dessas prerrogativas, o nível sociocultural e artístico, nos anos 90, passa a apresentar um novo perfil em sintonia com as mudanças sofridas. A cultura começa a ser contemplada como estrutura valiosa na configuração da identidade do país por meio de leis e incentivos fiscais, de forma que o mercado cultural vai se estruturando apoiado nos incrementos para produções artísticas. A velha etiqueta de uma arte de terceiro mundo se dinamita em várias direções. Tanto na forma de trabalhar as chamadas raízes regionais sintonizadas com o tempo presente, como também com a atualização das linguagens artísticas da contemporaneidade, suas antenas com o campo informativo, formal e tecnológico.

Adolfo Motejo Navas, em sua condição de observador espanhol da cultura brasileira, assinala que, os fomentos dos anos 90 favoreceram a produção brasileira tanto artística como teórica:

Estamos hablando también de un objeto estético como materia de reflexión, ya que en nuestros días ha ganado, o mejor dicho, ha reforzado esa capacidad, esa imperiosa obligación interpretativa (socio-lingüística y espiritual). Como algo que ya deja de ser objeto/obra y pasa a ser más poiesis, poética, creación, producto artístico, objeto en tránsito en busca de su propio paradigma. (2008, p. 73$)$

De alguma forma, o Brasil, desde os anos 20, com o advento do modernismo, já caminhava para esse reconhecimento estético ao reconciliar-se com a perspectiva histórica sem ter que buscar referências estrangeiras a qualquer preço. A partir dos anos 90, com a proliferação dos Estudos Culturais e os campos de estudos ampliados, os artistas e investigadores das novas gerações incorporam o compromisso do trabalho reflexivo (poética), exploração lingüística e sóciocultural à produção artística. Assim, a configuração dos anos 90 permite a incorporação de novos autores brasileiros no cenário espanhol, como também nomes de escritores já solidificados no Brasil, a saber, Machado de Assis, Autran Dourado, João Cabral, Nélida Piñon e a própria Lispector, como um legado para se discutir a natureza e a estética da literatura brasileira que deixava de estar condicionada ao regionalismo do país. Acrescenta-se a isso um reforço conceitual que inclui o lado antropofágico, de Oswald de Andrade, década de 20, reforçado pelo movimento do tropicalismo nos anos 60/70. O que os espanhóis chamam também de a canibalização do outro:

De alguna forma, se puede decir que el cuerpo artístico como tal se pone en relación, se flexibiliza en muchos brazos/extensiones; en el fondo, se articula, gracias a una intertextualidad cada vez más creciente y menos fundamentalista que en otros periodos, lo que representa una característica del arte contemporáneo, pues no rompe con el modernismo, no establece con él ningún par dicotómico. (Navas 2008, p. 76-77) 
Isso não quer dizer que para o leitor espanhol dos anos 90 Clarice fosse uma desconhecida, que sua literatura não tivesse sido fomentada nos contextos universitários e até estudada como uma obra de grande importância estética, o que era ainda desconhecida é a grandeza de uma autora dentro de uma variedade de produção qualitativa e intensa da literatura sul americana escrita em português. Nesse período, grande parte de sua obra é publicada, de manera que começa a haver um fomento nas produções teóricos-críticas e a literatura brasileira anteriormente conhecida como muito próxima à oralidade e vinculada a uma realidade sociológica, passa a se destacar por suas características estéticas.

Clarice vai alterar o traçado do mapa literário europeu propondo uma nova inserção do Brasil em contexto espanhol. Sua obra vai penetrar uma elite européia que passará a discutir e analisar novas formas de relações nas instâncias de produção, circulação e apropriação entre uma ex-colônia e uma metrópole. O professor e crítico literário Basílio Losada salienta que:

A partir de su muerte, en 1977, la obra de Clarice ha obtenido un reconocimiento universal. El reconocimiento relativo que puede obtener una literatura como la brasileña, inmensa y sugestiva quizá como ninguna otra de nuestro tiempo, pero que no tiene entrada en los circuitos del mundo editorial, quizá por su misma peculiaridad. (...) Hoy, nadie duda que la narrativa de Clarice Lispector constituye uno de los testimonios más profundos de nuestro tiempo, un intento, quizá sin esperanza, de expresar las contradicciones, los riquísimos matices, el misterio profundo del alma femenina. (Losada, 2008: 11-12)

Longe da oralidade e do folclore brasileiro, a obra clariciana é edificada na linguagem e nas relações humanas, mais especificamente na alma feminina. Losada também acrescenta em prefácio publicado na $4^{\mathrm{a}}$ edição da obra Cerca del corazón salvaje:

No creo que haya en ninguna literatura de nuestro tiempo un ejemplo tan perfecto de literatura de mujer, y quizá nadie ha llegado a una precisión, a veces incluso obsesiva pero plausible siempre, de las posibilidades de la palabra como manifestación de mundos interiores. (Losada, 2008: 9)

As obras de Clarice traduzidas para o espanhol atingem um universo significativo. A Agência Espanhola de ISBN, órgão equivalente ao do Brasil, registra 35 obras. Toda sua produção foi traduzida, inclusive a infantil, e atualmente se está traduzindo os livros que contem as cartas trocadas entre a escritora e seus parceiros culturais, bem como as cartas enviadas a suas irmãs.

Em 1977 é traduzido e publicado o primeiro livro de Clarice, Cerca del corazón salvaje, com tradução Basílio Losada, pela Editorial Caralt. Em 1988, pela editora Grijalbo se publica Silencio (Ondes estivestes de noite) e Felicidad Clandestina. No mesmo ano, pela editora Montesinos Editor é publicado Lazos de 
família, com tradução de Cristina Peri Rossi, também na cidade de Barcelona na Catalunha. Ainda em 1988 é traduzida por Alberto Villalba Rodrigues, pela editora Edicions 62 pasión según G.H., provavelmente a obra com maior fortuna crítica no país.

Em 1989 é publicado a obra La hora de la estrella, pela editora Siruela, em Madrid, traduzido por Ana Poljak, que verte para o espanhol, textos de várias línguas, como francês, italiano, inglês e catalão. São inúmeras suas traduções nas edições espanholas, porém, livros que partiram do original português, encontra-se apenas o de Clarice.

Depois disso, transcorre-se um período sem publicação da escritora brasileira e apenas em 1995 volta a ser publicada a mesma obra para o asturiano (Província de Astúria) com tradução de Antón Garcia pela editora Trabe. Também nesse mesmo ano é publicado Felicidad clandestina: silencio, com tradução de Elena Losada Soler pela editora Círculo de leitores, em Barcelona. Ainda em 1995 a editora Grijalbo publica por meio da coleção "Espejo de tinta", a obra Silêncio, com tradução de Cristina Peri Rossi.

Em 1996, é publicado novamente em asturiano A paixão segundo G.H., sob a coordenação de Benedito Nunes e da Editorial/es: Association Archives de la Littérature Latino-américaine des Caraïbes et Africaine du XXe siècle. Amis de M. A. Asturias - ALLCA XX-Colección Archivos.

Em 1997, a editora Grijalbo publica também Felicidad Clandestina, com tradução de Marcelo Cohen.

Em 1998 e 99 não ocorrem publicações, somente em 2000 é editado novamente La pasión según G. H., agora pela editora El Aleph situada também em Barcelona, com tradução de Alberto Villalba Rodrigues.

Em 2001 não há publicações, mas em 2002 a obra clariciana passa a ser publicada por uma prestigiosa editora, a Siruela, dirigida pela professora Elena Losada Soler, que herdou do pai o amor pelo Brasil e por Clarice, e vai editar (e reeditar) praticamente toda a obra da escritora. Começa com Aprendizaje o el libro de los placeres, com tradução de C. Sáenz de Tejada e J. García Gayo, que é, rapidamente, esgotado.

Em 2002, a editora Alfaguara de Madrid publica Cuentos reunidos, em um volume que reúne os contos da autora. Foram agregados os livros Lazos de família e Donde estuviste de noche? traduzido por Cristina Peri Rossi; La Legión estranjera, por Juan García Gayó; Felicidad clandestina por Marcelo Cohen; El vía crucis del cuerpo e La bella y la bestia por Mario Morales. A obra conta ainda com um prólogo de vinte páginas, elaborado pelo professor e crítico literário Miguel Cossío Woodward.

Em 2003, a editora Siruela volta a publicar. Dessa vez o romance La manzana en la oscuridad, com tradução de Elena Losada Soler, em Madrid.

Em 2004, a mesma editora, com a mesma tradutora, lança Água viva. 
Em 2005 é reeditado, pela Siruela, Cerca del Corazón Salvaje traduzido por Basílio Losada, constituindo a $3^{\mathrm{a}}$ impressão da obra e esgotando-se rapidamente.

Em 2006 o número de traduções e publicações de Lispector aumenta consideravelmente. A editora Pagés edita em catalão, língua restrita à província da Catalunha, os livros Aigua viva i l'hora de l'estrella com tradução de Josep Domènech Ponsatí; e a editora Empuries publica, na mesma língua La passió segons G. H. , com tradução de Núria Prats Espar. Também são publicadas em espanhol, pela Siruela mais duas outras obras: La ciudad sitiada e La lámpara, ambos traduzidos por Elena Losada Soler, perfazendo um total de quatro obras em um ano.

Em 2007 ocorre novamente um grande fluxo de publicações. A Editorial Cruilla, S.A. publica as obras La dona que va matar els peixos e El misteri del conill que pensava, ambos em catalão, com tradução de Natàlia Tomàs Anguera, e Enric Tudó Rialp, respectivamente. Ambos tiveram, como língua de partida, o português. Ainda no mesmo ano a editora Siruela edita Para no olvidar : crónicas $y$ otros textos, o que inclui crônicas, contos, e alguns pequenos textos que Clarice publicou em jornal e que talvez não se enquadre em nenhum dos gêneros anteriores, além de Aprendiendo a vivir : y otras crónicas, ambos com tradução de Elena Losada Soler.

Em 2008 ocorre a culminância de todo esse empreendimento de traduzir e publicar Clarice na Espanha. Novas editoras se interessam a publicar a literatura da brasileira perfazendo um número de oito livros publicados no mesmo ano. A editora Sabina cria um projeto para publicar toda a obra infantil, de forma que $L a$ mujer que mató a los peces, El conejo que sabía pensar, La vida íntima de Laura $e$ Casi de verdad, são traduzidos por Elena Losada Soler e podem ser lidos pelos leitores infantis de língua castelhana. Dos outros quatro, um é reedição de $L a$ pasión según $G H$, pela editora El Aleph. O outro é O Correio feminino que trata dos contos jornalísticos escritos por Clarice em jornais, a maioria sob pseudônimos, que é traduzido por Elena Losada Soler e publicado pela editora Siruella. Também pela Siruella é feita a terceira impressão de Aprendizaje o El libro de los placeres, traduzido por Juan García Gayo e Cristina Sáenz de Tejada e da obra póstuma Un soplo de vida : (pulsaciones) com tradução de Mario Merlino Tornini.

Em 2009, foram publicadas três obras. Uma nova publicação da obra La hora de la estrella, traduzida por Ana Poljak e publicada pela Siruella, já como a $5^{\text {a }}$ impressão. Y Donde se enseñará a ser feliz y otros escritos, cujo o original se chamou Outros escritos. A obra contem quatro contos de uma escritora ainda principiante, além de textos escritos enquanto jornalista, estudante de direito, dramaturga, colunista feminina, ensaísta, tradutora, conferencista e entrevistada. $\mathrm{O}$ livro tem prólogo e comentários das brasileiras Teresa Montero e Lícia Manzo.

Também a editorial Sabina publica Cómo nacieron las estrellas : doce leyendas brasileñas, uma obra infantil pouco conhecida em português. Trata-se de 
doze lendas brasileiras e que, no Brasil, pode ser encontrada em $\mathrm{CD}$, inclusive com um conto narrado pela voz da neta de Clarice Lispector e outros com atores brasileiros. Na Espanha pode ser encontrado em livro com tradução de Elena Losada Soler.

$\mathrm{O}$ alto número de publicações, inclusive alguns livros com duas traduções, gerou um número relativo de estudos da obra da escritora brasileira em várias universidades espanholas, também textos críticos publicados em revistas e jornais de grande circulação, teses e um número crescente de leitores comuns que se pronunciam em blogs, grupos de leituras e outras discussões produzidas por meio de ferramentas da Internet. Diante desse pequeno mapeamento pode-se dizer que a obra de Clarice vem contribuindo para que a literatura brasileira seja, na Espanha, um dos segmentos culturais mais ricos, intensos e instigantes, perdendo apenas para a música que, diga-se, é a atividade artística brasileira mais reconhecida mundialmente.

À guisa de conclusão, cito as palavras da professora e filósofa Mirian Jimenes Quenguan que pergunta, em sua obra Clarice Lispector y María Zambrano: El pensamiento poético de La creación: “¿Clarice de donde viene?” Ela mesma responde:

Viene de una estrella desgarrada, de un instante que grita la palabra y aspira al necesario e indecible silencio. Procede de distintos mundos, quizá de muchas vidas; Ella misma decía, hay varias vidas en la vida. Es la unión de diversas geografías, idiomas, pensamientos y creencias; es la acción del portugués, su lengua materna que siempre redescubre y es también la traducción de infinitos lenguajes que entran a configurar su propio universo. (...) Clarice es mestizaje geográfico, humano, lingüístico. (Jimenes Quenguan, 2009, p. 30-31)

\section{Referências bibliográficas}

CASANOVA, Pascale. Le republique mondiale des lettres. Paris: Seuil, 1999.

CRESPO, Ángel. Proshomenaje. Revista de cultura brasileña: el mundo mágico de João Guimarães Rosa. Embajada de Brasil en Madrid, febrero 2007, $\mathrm{n}^{\circ}$ 5, nueva serie.

JiMENEZ QUENGUAN, Myriam . Clarice Lispector y María Zambrano: el pensamiento poético de la creación. Colección Cuadernos inacabados, 59. Madrid: horas y HORAS, 2009.

LOSADA, Basílio. Introducción. Cerca del corazón salvaje. Madrid: Ediciones Siruela, 2008, $4^{\mathrm{a} e d}$.

MAURA, António. El discurso narrativo de Clarice Lispector (Tese doutoral) Madrid: Universidade Complutense, 1997.

. Recepción en España de Gran sertón: veredas. Revista de cultura brasileña: el mundo mágico de João Guimarães Rosa. Embajada de Brasil en Madrid, febrero $2007, \mathrm{n}^{\circ} 5$, nueva serie. 
MONTEJO NAVAS, Adolf. 7 notas de navegación para uma cartografia del arte reciente em Brasil. Revista de Cultura Brasileña: cartografias estéticas, arte en Brasil hoy. Embajada de Brasil em Madrid, febrero 2008, nº 6 nueva serie.

OsWALDO CRUZ, Gilda. "Clarice Lispector, cerca de su corazón salvaje". Revista Quimera, Barcelona, s/d.

VENUTI, Lawrence. Escândalos da tradução. Trad. Laureano Pelegrin; Lucinéia Marcelino Vilela; Marileide Dias Esqueda; Valéria Biondo. Bauru-SP: EDUSC, 2002.. 